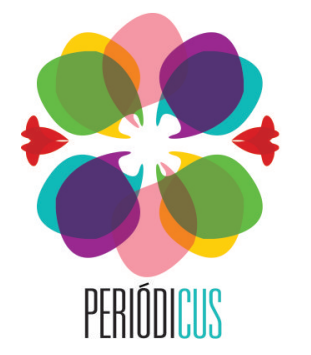

\title{
A feminilidade em discurso: mídias musicais contemporâneas produzindo modos de ser jovem e mulher
}

\author{
Juliana Ribeiro de Vargas $^{1}$ \\ Maria Luisa Merino Xavier ${ }^{2}$
}

Resumo: O presente estudo visa analisar e problematizar de que modo a experiência de ser aluna jovem, na contemporaneidade, tem sido atravessada por discursos visibilizados em mídias musicais acessadas por alunas do último ano do Ensino Fundamental, estudantes de uma escola da periferia. É importante referir que tais mídias estão armazenadas nos cartões de memória dos aparelhos celular das referidas alunas e são acessadas por elas em diversos momentos da rotina escolar. A partir das perspectivas teóricas dos Estudos Culturais e dos Estudos de Gênero, com o apoio de metodologias de cunho etnográfico, constituímos duas categorias analíticas, sexualidade e ostentação/ consumo. Nas mesmas são evidenciados e problematizados discursos e suas possíveis relações com a subjetivação das jovens. Por fim, afirmamos acreditar na relevância, pedagógica e social, de estudos que investiguem posicionamentos e comportamentos de alunas contemporâneas a fim de sejam constituídas práticas pedagógicas diferenciadas, contemplando as exigências das legislações vigentes e ainda as necessidades específicas de cada grupo de estudantes.

Palavras Chave: Gênero; Estudos Culturais; Discurso

\begin{abstract}
The present study aims to analyze and discuss how the experience of being a young student nowadays, has been affected by visualized speeches in musical media accessed by students of the final year of elementary school, who attends a school on the outskirts. It is important to note that such media are being stored in the memory card of the students' mobile handsets and they are accessed in several moments of the school routine. From the theoretical perspectives of Cultural Studies and Gender Studies, with the support of ethnographic methodologies, we've established two analytical categories, which are sexuality and ostentation / consumption. In them, are shown and problematized discourses and their possible relationships with the subjectivity of the young. Finally, we assert to believe in the pedagogical and social relevance of studies that investigate positioning and behaviors on contemporary students, in order to constitute differentiated teaching practices, covering the requirements of current legislation and moreover, the specific needs of each group of students.
\end{abstract}

Keywords: Gender; Cultural Studies; Discourse

Resumén: El presente estudio tiene como objetivo analizar y discutir cómo la experiencia de ser una joven estudiante en la actualidad, se constituye por los discursos presentes en los medios musicales que son accedidas por los alumnas del último año de la escuela primaria, estudiantes de uma escuela publica de periferia. Es importante señalar que este tipo de medio musicales están siendo almacenados en las tarjeta de memoria de los teléfonos móviles de los estudiantes y que ellas se acceden a ellos en varios momentos de la rutina escolar. Desde las perspectivas teóricas de los Estudios Culturales y de los Estudios de Género, con el apoyo de metodologías etnográficas, hemos establecido dos categorías de análisis, que son la sexualidad y la ostentación / consumo. En ellos, se muestran y se problematiza discursos y sus posibles relaciones con la subjetividad de los jóvenes. Por último, afirmamos creer en la importancia pedagógica y social de los estudios que investiguen los posicionamiento y comportamientos de las estudiantes contemporáneas, con objetivo de constituir prácticas de enseñanza diferenciadas, que cumplan los requisitos de la legislación actual y todavia, las necesidades específicas de cada grupo de estudiantes.

Palabras clave: Género. Estudios Culturales; Discurso

1 Mestre e doutoranda em Educação pela Linha de Pesquisa Estudos Culturais em Educação (PPGEDU/UFRGS).

E-mail: julivargas10@hotmail.com

2 Mestre e doutora em Educação pela Universidade Federal do Rio Grande do Sul. E-mail: mlxavier@uol.com.br 
Mas, a normalista linda

Não pode casar ainda

Só depois que se formar...

Eu estou apaixonado

O pai da moça é zangado

E o remédio é esperar

Normalista - Nelson Gonçalves e David Nasser (1949)

A menina má só quer aquele que com certeza vai bancar

Vai ter que dar tudo que papai e mamãe parou de dar

Ela quer tatuagem, ela quer carinho,

andar nos melhores lugares, quer também carro novinho

Menina Má - Mc Duduzinho (2011)

\section{Primeiros acordes}

Pouco mais de sessenta anos separam o lançamento no mercado fonográfico nacional das músicas acima referidas. Em ambas, a temática do comportamento feminino é destacada. Contudo, enquanto a jovem normalista, ao final dos anos de 1940, é descrita como aquela que deve esperar a conclusão do Curso Normal para poder se casar, as jovens da segunda década do século XXI são descritas como aquelas que se interessariam, supostamente, por homens que tenham condições de satisfazer seus desejos e vontades. É interessante notar que, mesmo após mais de seis décadas, a relação referida naquelas músicas acaba por ser, de algum modo, semelhante, uma vez que ambas descrevem ações e possibilidades de vida de jovens mulheres como dependentes do chamado mundo masculino. Seja pela necessidade de aprovação do pai ou, ainda, pelos benefícios (principalmente materiais) que um relacionamento com um homem rico poderia proporcionar, as letras das músicas acabam por descrever jovens, tanto dos anos de 1940 quanto de 2011, que parecem não conseguir conduzir suas vidas de maneira independente de uma figura masculina. ${ }^{3}$ No entanto, vale questionar: é possível afirmar que as mulheres na atualidade, de um modo geral, em especial as adolescentes e jovens, conduzem suas vidas, seus relacionamentos pautados sobre tal normativa?

Os campos teóricos dos Estudos Culturais e dos Estudos de Gênero, em vertente pós-estruturalista, selecionados para subsidiar este estudo, permitem o aprofundamento de tal discussão. Em consonância com tais campos de estudo, os sujeitos são constituídos e diferenciados discursivamente, segundo as condições de possibilidades de distintos contextos históricos e sociais. As jovens contemporâneas estariam sendo subjetivadas de diferentes modos em seus relacionamentos amorosos, em suas possibilidades de vida, em suas feminilidades pelos diferentes discursos que as atravessam, tanto os referentes à dependência masculina como os pautados pela perspectiva feminista que ressaltam o protagonismo e o empoderamento feminino contemporâneo.

3 Vale aqui referenciar a narrativa de uma estudante participante desse estudo. Sua fala, ao descrever os relacionamentos amorosos de uma colega de classe, corrobora as afirmações acima mencionadas: "É que eu vou te explicar uma coisa [...], hoje em dia é assim [...] ela te falou, ela pega patrão. 'Os patrão' se tu 'solta' alguma coisa para eles, eles vão te dar outra em troca, por isso que eles dão coisas para ela.” (Diário de campo, 30 maio de 2012) 
O presente estudo, recorte de uma investigação mais ampla, tem como objetivo analisar e problematizar de que modo a experiência de ser aluna jovem, em escolas de periferia da Rede Municipal de Porto Alegre, especificamente, tem sido atravessada pelos discursos visibilizados por artefatos musicais, armazenados nos cartões de memória dos aparelhos celulares de um grupo de alunas do último ano do Ensino Fundamental. Torna-se importante enfatizar que ao referir-nos à experiência, aproximamo-nos das compreensões de Michel Foucault (2009) e de Jorge Larrosa (1994, 2002) sobre a temática.

Segundo Larrosa, os processos de experiência de si, assim como os processos de subjetivação, estão relacionados às diversificadas experiências culturais com quais os sujeitos têm contato, pois, como afirma o autor, “[...] toda cultura deve transmitir certo repertório de modos de experiência de si, e todo novo membro de uma cultura deve aprender a ser pessoa em alguma das modalidades incluídas nesse repertório." (LARROSA, 1994, p. 10). A partir desta premissa e de acordo com as afirmações anteriores, entendemos a análise dos artefatos culturais com os quais as alunas têm contato - as músicas que as mesmas armazenam e escutam em seus aparelhos celulares - como estratégia importante para a compreensão de modos de experiência de si de tais jovens.

Pretende-se compreender melhor até que ponto os discursos visibilizados pelas músicas escutadas pelas alunas produzem modos de viver a feminilidade na atualidade, em especial, no contexto das periferias urbanas, espaço no qual estão localizadas um grande número de escolas das redes públicas de ensino. É importante destacar que, segundo Antônio Flávio Moreira e Paulo Melgaço da Silva Junior (2010), estudar as periferias urbanas coloca-se como um caminho profícuo para a análise das práticas sociais vividas pelos moradores que nelas habitam e também para compreensão dos discursos circulantes em tais espaços.

A partir de inserções em espaços da escola pública e em diferentes eventos de formação docente, pontuamos que são expressivas as dúvidas e também os anseios de professores, no trabalho curricular com as questões de gênero e sexualidade. De igual modo compreendemos que a constituição das diferentes feminilidades contemporâneas coloca-se como uma temática complexa a ser mais bem analisada e compreendida pelos docentes, uma vez que os mesmos não sabem como agir quando, por exemplo, uma aluna de treze anos, na sala de aula, afirma ter um piercing genital ou, ainda, quando outra afirma não querer mostrar as imagens de seu celular, pois ali estariam postadas fotos dela e de sua namorada. ${ }^{4}$

As questões de gênero e sexualidade já abordadas, de certa forma, na década de 1990, nos Parâmetros Curriculares Nacionais (PCNs), no volume Pluralidade Cultural e Orientação Sexual e, hoje, nas Diretrizes Curriculares Nacionais da Educação Básica (DCNE), promulgadas pelo MEC a partir de 2010, continuam desafiando a escola, uma vez que as teorizações e estudos sobre o tema ainda não oferecem, segundo os docentes, subsídios suficientes para enfrentamento das situações vividas em

4 Tais narrativas são de autoria de alunas participantes deste estudo, protagonizadas, assim como as demais, entre os meses de abril, maio e junho de 2012. 
tais instituições. ${ }^{5}$ Para Claudia Maria Ribeiro, nossa herança cultural poderia responder em parte por esta dificuldade:

Nossa herança cultural deixou impregnada em nossos corpos as relações entre o pecado e a carne; sexo e sexualidade restritos à genitalidade. A imposição de limites, de penalidades, de culpas reduziu a sexualidade ao que pode, ao que não pode, ao que é adequado e ao que é inadequado; ao que é normal e ao que é patológico. (RIBEIRO, 2008, p. 239)

Entendemos também que a problematização das feminilidades contemporâneas visibilizadas nas posturas de alunas, principalmente daquelas que residem nas periferias urbanas, se faz necessária, uma vez que tais posturas diferem, em determinadas situações, do ideário feminino naturalizado, desestabilizando, assim, a prática pedagógica de muitos docentes. A fala da aluna Larissa, de treze anos, coloca-se como exemplo da diferenciação acima referida, pois tenciona duas características naturalmente relacionadas às mulheres: a fidelidade a um parceiro específico e a passividade frente aos conflitos:

Larissa: Se alguém me chamasse de sabonete eu metia um "tapaço" na cara! Mesmo que eu fique com um monte de guri, tipo: uma hora eu "tô" com um, outra hora eu "tô" com outro, mesmo que... não é motivo para "tá" me chamando de sabonete. [...] Eu "tô" lá ficando com um guri, vai lá, vem outro e me chama: bah! sabonete, eu vou lá e... Não dá certo, isso aí sora!

Pesquisadora: Tu já brigas?

\section{Larissa: Ahã!! ${ }^{6}$}

A partir de pronunciamentos como os acima referidos acreditamos na relevância pedagógica e social de estudos que investiguem posicionamentos e comportamentos de alunas contemporâneas a fim de sejam constituídas práticas pedagógicas diferenciadas, contemplando as exigências das legislações vigentes e, ainda, as necessidades específicas de cada grupo de estudantes. Propomos, com o apoio das ferramentas teóricas já destacadas, como alude Alfredo Veiga Neto (2012), "ir aos porões" a fim de compreender os atravessamentos de diferenciados discursos na constituição de feminilidades juvenis contemporâneas, e, por conseguinte, nos modos de experiência de si assumidos pelas jovens alunas. Análises nessa abordagem, conforme afirma o mesmo autor (VEIGA NETO, 2012, p.279), promovem o combate aos "estereótipos e preconceitos, sempre tão comuns e danosos tanto para uma compreensão mais acurada e consequente dos fenômenos sociais.”

Nas seções a seguir serão apresentadas, respectivamente, as perspectivas teórico-metodológicas que assumimos neste estudo. Posteriormente apresentaremos recortes das letras de determinadas

5 Diretrizes Curriculares Nacionais são o conjunto de definições doutrinárias sobre princípios, fundamentos e procedimentos na Educação Básica, expressas pela Câmara de Educação Básica do Conselho Nacional de Educação, que orientarão as escolas brasileiras dos sistemas de ensino, na organização, na articulação, no desenvolvimento e na avaliação de suas propostas pedagógicas. De acordo com documento referente às resoluções da Educação Básica, as questões de gênero, etnia e diversidade cultural, bem como as ações educativas produzidas sobre as temáticas, devem ser contempladas no Projeto Político de cada instituição de ensino. Ver: Resolução CNE/CEB n n 4, de 13 de julho de 2010. Disponível em:

http://portal.mec.gov.br/index.php?option=com_content\&view=article\&id=14906\&Itemid=866. Acesso: 01 de jun. 2012. 6 Por razões éticas os nomes das alunas são fictícios e foram escolhidos por cada uma das participantes deste estudo. Conversações ocorridas em 28 de jun. 2012. 
músicas escutadas pelo grupo de alunas investigado, compreendendo que as mesmas visibilizam discursos acerca de categorias tais como sexualidade e consumo, as quais parecem estar imbricadas na constituição dos modos de viver/compreender as feminilidades contemporâneas. Encerramos este texto pensando que as análises sobre posicionamentos e posturas das estudantes participantes deste estudo podem permitir melhor conhecê-las e inspirar a organização de práticas pedagógicas diferenciadas, mais próximas da realidade de vida das mesmas.

\section{Discursos que conduzem e produzem: o caminhar teórico-metodológico}

Conforme afirmado anteriormente, os Estudos Culturais e os Estudos de Gênero, em uma perspectiva pós-estruturalista, constituem as trilhas principais usadas para o desenvolvimento do presente estudo. Como pontuam Cary Nelson e demais autores (1995), o campo dos Estudos Culturais visa à desconstrução das relações hierárquicas entre alta e baixa cultura, desassociando o conceito de cultura exclusivamente das produções de determinados grupos sociais, denominadas como produções de alta cultura ${ }^{7}$. Logo, desde o princípio, os Estudos Culturais configuram-se como espaços para a problematização de relações dicotômicas, fundamentadas pelas tradições elitistas, tais como alta cultura x cultura de massa; cultura burguesa x cultura operária e entre cultura erudita x cultura popular. (COSTA, SILVEIRA, SOMMER, 2003). Assim, é possível afirmar que, para o campo dos Estudos Culturais, todas as manifestações significativas para os distintos grupos sociais podem ser compreendidas como produções culturais, como é o caso das músicas escutadas pelas alunas desse estudo em seus celulares. Vistas como ações comunicativas/identitárias dos grupos sociais nos quais elas transitam, tais músicas são compartilhadas através da internet ou ainda, pela tecnologia bluetooth ${ }^{8}$

As pesquisas constituídas no referido campo buscam analisar e problematizar os efeitos das estruturas econômicas e políticas nas sociedades e nas suas produções culturais, (ESCOSTEGUY, 2001). Na mesma linha de argumentação, apropriando-se de conceitos de Antônio Grasmci, Stuart Hall (1997) compreende a cultura como espaço de luta ideológica, palco da incorporação e resistência; um dos locais nos quais se constitui a hegemonia.

Os aportes dos Estudos de Gênero permitem-nos problematizar questões tais como a naturalização de comportamentos femininos a partir de determinadas características, as reduzidas possibilidades de participação social à disposição das mulheres ao longo dos tempos e, também, a submissão das mulheres frente aos ordenamentos masculinos. Frente ao conceito de gênero compreendemos homens e mulheres como categorias constituídas para além das diferenciações biológicas, nas quais as caracterizações organizadas na cultura diferem em diferentes tempos e sociedades. Como afirma Joan Scott (1995), o conceito de gênero pode ser entendido como um elemento constitutivo das relações sociais baseadas nas diferenças percebidas entre os sexos e como uma forma primária de dar significado às relações de poder.

\footnotetext{
$7 \mathrm{O}$ conceito de cultura associado às produções de determinados grupos sociais foi constituído, principalmente, ao longo da Modernidade. Deste modo, “[...] que a cultura designava o conjunto de tudo aquilo que a humanidade havia produzido de melhor - fosse em termos materiais, artísticos, filosóficos, científicos, literários, etc. Nesse sentido, a cultura foi durante muito tempo pensada como única e universal.” (VEIGA-NETO, 2003, p. 7).

8 Presente em grande parte dos aparelhos celulares na atualidade, a tecnologia bluetooth permite transmissão de dados e arquivos sem a necessidade de fios entre aparelhos de telefone celular, notebooks, computadores entre outros equipamentos.
} 
Em consonância com as ideias de Scott (1995), Teresa de Lauretis (1994) compreende o conceito de gênero para além da associação entre as diferenças sexuais, uma vez que para ela também aquelas não são universais, não sendo articuladas em razão de essências únicas. A partir de tais formulações, Lauretis aproxima o referido conceito às teorizações de Foucault constituídas principalmente nos volumes da História da sexualidade:

[...] assim como a sexualidade, o gênero não é uma propriedade de corpos nem algo existente a priori nos seres humanos, mas nas palavras de Foucault, [relacionase ao] 'conjunto de efeitos produzidos em corpos, comportamentos e relações sociais' por meio do desdobramento de 'uma complexa tecnologia política'. (LAURETIS, 1994, p. 208)

\section{Os passos metodológicos}

O material empírico dessa investigação decorre de observações participantes realizadas com um grupo de jovens alunas, estudantes de uma escola pública localizada em uma região de periferia, com idades entre treze e quinze anos ${ }^{9}$. Ao longo de observações com o referido grupo, foi possível verificar a forte inserção do aparelho celular como ferramenta de comunicação e artefato midiático utilizado pelas estudantes. Ações como trocar mensagens, conversar com colegas, realizar os exercícios de determinada disciplina e ainda ouvir música no celular pelo fone de ouvido (burlando muitas vezes o olhar do professor) tornaram-se atividades características e comumente praticadas pelos estudantes dos tempos atuais. Na atualidade, os jovens alunos conseguem comunicar-se de diversificadas formas, sob diferentes tecnologias, em uma velocidade ímpar (GARBIN, 2009).

Em referência aos aparelhos celulares, também é possível pensar que, de modo semelhante aos chamados diários de outros tempos, os mesmos prestam-se ao registro de memórias/vivências das jovens alunas, uma vez que imagens e músicas que remetem aos ídolos, amores e amigos ficam registradas nos cartões de memória de cada aparelho. É possível pensar tais registros imagéticos e musicais como modos através dos quais as alunas se constituem e são subjetivadas em sua existência. Contudo, é importante pontuar a provisoriedade e a flexibilidade que tal recurso comporta, uma vez que cada aluna costuma possuir mais de um cartão de memória e tem a possibilidade de constantemente registrar e apagar seus arquivos.

Podemos pensar que os registros de tais alunas constituam memórias fragmentadas, distantes da ideia de totalidade cara à modernidade. A fim de entender melhor a constituição dessas memórias, é preciso, como afirma Zygmunt Bauman (2001), abandonar toda a esperança de totalidade, seja esta passada ou futura, uma vez que as mesmas poderiam ser descritas como 'memórias fluídas'.

O elevado número de registros musicais nos cartões de memória foi um dos aspectos que chamounos a atenção, pois muitas alunas armazenavam mais de uma centena de músicas em um mesmo cartão. Tais mídias circulavam entre as alunas através da tecnologia bluetooth, ou ainda por programas de acesso e transferência do conteúdo da web para artefatos tais como computadores,

9 Instituição na qual uma das pesquisadoras trabalha como professora. 
celulares, aparelhos de MP3 e MP4. ${ }^{10}$ A possibilidade de ter um número elevado de músicas nos seus celulares foi destacada pelas alunas como força motivadora para o acesso/troca de tais mídias, como descreve Suzana (13 anos): “Às vezes eu nem sei que música eu "tô" pegando [...] Eu gosto de ter bastante música no meu celular para quando eu vou viajar. Gosto de ficar escutando!”. Tal ideia é reiterada por Evillyn (15 anos): "Eu nem escuto tudo, eu ponho várias músicas para o meu cartão de memória ficar cheio, para ter várias músicas!"11

A estratégia de acesso, registro e análise dos arquivos musicais foi complementada pelas conversações realizadas com algumas alunas sobre tais registros. Valemo-nos do termo conversação a fim de descrever os momentos em que as alunas apresentavam suas opiniões acerca dos temas presentes nos seus cartões de memória, bem como sobre outras temáticas. Manuel Jacinto Sarmento (2011) busca em Peter Woods (1987) a referência para pautar sua opção pelo uso do termo conversação em detrimento de entrevista, pontuando que em uma “[...] investigação etnográfica só faz sentido uma comunicação afável [...]", na qual os indivíduos podem se manifestar como são (SARMENTO, 2011, p. 162).

Ao conversamos com as alunas, a maior parte das mesmas afirmavam que "ouvem de tudo um pouco", destacando os gêneros funk, hip-hop e pagode como preferidos. Procuramos destacar, nas seções abaixo, como tais mídias musicais visibilizam determinadas categorias, a exemplo da sexualidade e da ostentação de bens consumo, entre tantas outras, organizando possivelmente modos de ser jovem aluna e de viver a feminilidade na contemporaneidade.

\section{4. É uma botada e tchau! Uma forma de sexualidade em evidência}

Segundo Foucault, o termo sexualidade surge como discurso no início do século XIX relacionado, entre outros fenômenos, ao desenvolvimento de áreas de conhecimentos diversas que "[...] cobriram tanto os mecanismos biológicos da reprodução como variantes individuais ou sociais do comportamento [...]" (FOUCAULT, 2009, p. 10). É possível perceber também que a difusão, principalmente nas sociedades ocidentais de determinadas regras e normas, sobre as quais instituições como igrejas, hospitais e escolas, passam a apoiar suas ações, parece estar relacionada às mudanças nas significações que os indivíduos relacionam aos seus deveres e prazeres, também como fenômenos relacionados ao discurso da sexualidade.

Para o referido autor, a sexualidade também pode ser compreendida como um dispositivo histórico articulado por estratégias de saber-poder as quais regulam corpos, prazeres, discursos, controles e resistências (FOUCAULT, 2007). E é na conceituação do sexo que o dispositivo da sexualidade e, por conseguinte, a sua produção discursiva, apoia-se para operar. Logo, o sexo constitui um elemento do dispositivo da sexualidade, o qual está intimamente relacionado às relações de poder estabelecidas em uma sociedade. (BUTLER, 2008).

Pensamos ser importante destacar que muitas das músicas relacionadas ao funk apresentam letras com expressões que denotam formas de relacionamento nos quais a vivência da sexualidade é explicita,

10 Ares, Emule, Pirate, MP3Rocket são exemplos de programas utilizados para copiar as músicas.

11 Conversação de 24 de maio 2012. 
uma vez que as palavras utilizadas pelos seus intérpretes visibilizam práticas relacionadas ao próprio ato sexual, tal como é possível perceber no excerto abaixo, retirado do celular de Eduarda (13 anos).

Hoje eu vou trair tra-trair-tra-trair

Fazer tudo que quero que-quero que-quero

Pra que compromisso?

Se eu não quero nada sério?

E-E-Entra no clima tá amor?

[Refrão]

É so uma botada e tchau

Botada e tchau (Botada e tchau - Os Hawaianos)

Outro exemplo relacionado ao mesmo tema refere-se às letras das músicas cantadas por Mr Catra, por Mc G7 e pelo grupo Gaiola das Popozudas, encontradas na maior parte das memórias eletrônicas das alunas. Tais letras chamam a atenção pelo seu conteúdo lascivo como pode ser percebido em expressões tais como: "Venha apagar teu fogo na mangueira do negão", "passa o pau na cara dela" e ainda, "Vai ter que engolir tudo, que é pra não sujar o banco". ${ }^{12}$

É interessante destacar que a música Poxa vida! cantada por $M c$ Roba Cena, refere a mesma temática, nas quais expressões como "empina a bunda porque sabe que me estica" e "Ela estica todo mundo com esse corpinho" referem-se à uma postura feminina que provoca a ereção masculina. No Youtube é possível encontrar versões da mesma nas quais apenas a imagem congelada do intérprete aparece. No entanto, no mesmo canal da web, podem ser encontradas versões, de livre acesso aos internautas, que focam, exclusivamente, nádegas femininas.

Um contraponto, interessante para ser problematizado, está na música Que bom que você chegou, associada ao gênero Gospel Religioso. A música referida evidencia, através de sua letra, a felicidade encontrada por uma mulher no matrimônio, o qual é descrito pela canção como "um presente de Deus". ${ }^{13} \mathrm{O}$ que chama a atenção é que ela é compartilhada entre alunas que escutam ao mesmo tempo músicas de conteúdo lascivo como Captiva ou Vera Cruz ou ainda, Senta, senta no cabeção. Ou seja, as mesmas alunas que cantam Vai mamar na Captiva parecem também ter prazer em ouvir uma música na qual o matrimônio é apresentado como a promessa de felicidade plena enviada por Deus.

Além das músicas relacionadas ao funk, as associadas ao gênero pagode também foram amplamente encontradas nos cartões de memória analisados. As músicas mais escutadas desse gênero tematizam o modo como alguns homens vivenciam relacionamentos amorosos com as mulheres. Em especial

12 Mr. Catra é o nome artístico de Wagner Domingues da Costa, funkeiro carioca. Produziu um documentário autobiográfico disponível na web desde 2010. Vide : http://www.youtube.com/watch? $\mathrm{v}=\mathrm{zG} 3 \mathrm{oERMnIXo}$. (Acesso em: 01 jul. 2012). Também nascida no Rio de Janeiro, Valesca Reis Santos, mais conhecida como Valesca Popozuda, é cantora, dançarina e vocalista do grupo de funk Gaiola das Popozudas, o qual, segundo a página do mesmo disponível na web, é o grupo de funk feminino mais forte do país. Vide http://www.gaioladaspopozudas.com.br/home.html. (Acesso em 05 de abr.2013). Em relação ao cantor Mc G7 não foram encontradas maiores informações, a não ser suas páginas nas redes sociais.

13 A música de Bruna Karla cantora gospel pode ser visibilizada em http://letras.mus.br/bruna-karla/1478633/. Acesso em 15 jan. 2012. 
tais músicas descrevem determinadas ações como características do momento do galanteio, da conquista, a qual acaba por ser descrita como uma prática naturalmente administrada pelo homem como é possível observar nos excertos abaixo: ${ }^{14}$

Já comprei até buquê de flores

E uma roupa nova pra te ver

Rosas lindas de todas as cores

Especialmente dedicadas a você (Buquê de Flores - Thiaguinho)

Ela é maravilhosa

Tem um sorriso maroto

O que será que ela tá querendo?

Vou chamar pra dançar,

Vem cá mulher, vem cá

Dançar, comigo agarradinho vem cá (Assim você mata o papai - Sorriso

Maroto)

É interessante perceber que tais músicas, de modo semelhante a algumas relacionadas ao gênero funk, operam, a partir de uma mesma matriz discursiva, pautadas por características tais como: a) os relacionamentos afetivos realizam-se, unicamente, dentro da ordem heterossexual; b) é evidenciado, nas relações descritas, um protagonismo masculino, uma vez que os homens são referidos como ativos nas situações de conquista. E, ainda, as mulheres são apresentadas como se fossem objetos "a serviço" da satisfação masculina. Dessa forma, é possível pensar que tais características sejam produzidas a partir de uma razão heteronormativa, uma vez que são reiteradas por discursos outros, a exemplo dos discursos religioso e biológico, e são operadas nessas diferentes ordens e objetivam fixar determinados comportamentos, ações como naturais para homens e mulheres. ${ }^{15}$

Segundo Jeffrey Weeks (2010), a significação do que seria normalidade e, por conseguinte, a definição da anormalidade em relação às identidades sexuais e ao exercício da sexualidade, foram elementos importantes para a distinção entre a homossexualidade e a heterossexualidade, ocorrida entre os séculos XIX e XX. Logo, a constituição de uma adequada identidade sexual feminina, bem como de um modelo de sexualidade masculino, estiveram relacionados à produção da heterossexualidade. De acordo com Luís Henrique S. Santos (2007), a heteronormatividade organiza um "[...] padrão de sexualidade que tem a qualidade e força de uma norma." (SANTOS, 2007, p. 25), o qual é produzido na associação entre o sexo, o gênero e a orientação sexual, estabelecendo assim posições dicotômicas e binárias (SEFFNER, 2013).

Segundo Jeffrey Weeks (2010), a significação do que seria normalidade e, por conseguinte, a definição das anormalidades em relação às identidades sexuais e ao exercício da sexualidade, foram

14 De autoria de Pezinho e Thiaguinho, Buquê de Flores é conhecida na voz de Thiaguinho. Já a música Assim você mata o papai é de autoria de Nicco Andrade e é cantada pelo grupo Sorriso Maroto. Vale destacar que tal música foi tema de um personagem da novela Avenida Brasil, de João Manuel Carneiro, exibida pela TV Globo no horário das $21 \mathrm{~h}$, entre 26 de março e 19 de outubro de 2012.

15 Apresentado por Michael Warner no início dos anos 1990, o conceito heteronormativo "está assentado em um sistema binário, dicotômico de caracterização e pressupõe dois modelos estritamente definidos com base na genitália: macho ou fêmea." (SANTOS, 2007, p. 26) 
elementos importantes para a distinção entre a homossexualidade e a heterossexualidade, ocorrida entre os séculos XIX e XX.

Assim, em nossa sociedade, conforme percebemos nos exemplos elencados, "os homens são os agentes sexuais ativos; as mulheres, por causa dos seus corpos altamente sexualizados, ou apesar disso, [são] 'despertadas para a vida' pelos homens." (WEEKS, 2010, p. 41) A "problemática" ocorre, muitas vezes, quando os jovens e as jovens, os homens e as mulheres, diferem em seu modo de viver de formas entendidas como naturalizadas para ser e agir. Ou seja, quando suas posturas diferem de uma lógica heteronormativa.

\section{Correria traz fartura: a ostentação como possibilidade de existência}

Em algumas das músicas analisadas, o aspecto que mais chama a atenção refere-se à ostentação, protagonizada por homens jovens oriundos de um contexto de periferia, de diversos adornos e bens de consumo. Tais músicas traçam, em sua maioria, narrativas acerca de "benefícios" que o acúmulo de patrimônio proporciona a esses jovens, a saber: a companhia de belas mulheres e a elevação de um status frente aos demais. A música Onde eu chego eu paro tudo, interpretada pelo $M c$ Boy do Charmes ${ }^{16}$, exemplifica nossas afirmações, ao narrar que o uso de uma série de artefatos de vestuário e embelezamento de valor extremamente elevado, de marcas como Dior, Lacoste, Armani, Oakley e Hilfinger, possibilitaria aos homens encantar, seduzir e compartilhar da companhia de belas mulheres.

O uso de adornos, como cordões e correntes de ouro, e ainda a propriedade de carros e motos de valor elevado também são destacados pela música referida como ações potenciais para a elevação do status de quem os usa. A versão audiovisual (videoclipe) dessa e de outras semelhantes visibilizam homens jovens cercados de belas mulheres e ostentando os artigos de luxo como os citados. ${ }^{17} \mathrm{~A}$ seguir, apresentamos excertos da música que evidenciam nossas afirmações.

[...] Meu cordão é um absurdo

Meu perfume é da Armani

De Christian ou de Oakley

De Tommy ou de Lacoste

De CB1000 da Honda

Ou de Hyundai Veloster

Correria traz fartura

Fartura traz alegria

E no meu vocabulário

Não existe economia

16 Mc Boy do Charmes é o nome artístico de Wellington França, cantor e compositor de música funk. 17 Podemos referir aqui as músicas Megane (Mc Boy do Charmes), Plaque de 100 (Mc Guime), É o fluxo (Mc Nego Blue) e as Minas do Camarote (Mc Dedé). 
Nós investe no poder

E usufrui da putaria (Onde eu chego eu paro tudo- Mc Boy do Charmes)

É interessante referir as condições de emergência do gênero funk na sociedade brasileira, as quais são associadas às classes sociais de menor poder aquisitivo e, por conseguinte, com uma suposta menor possibilidade de aquisição de bens de consumo. Segundo Michael Herschmann (2005), apesar de ter sido visibilizado na década do 1970 em na conhecida casa de espetáculo Canecão, o funk encontrou o seu espaço posteriormente nos bairros dos subúrbios cariocas. Nos tempos atuais, é possível afirmar que o referido gênero é produzido/consumido por "diversos grupos e segmentos sociais, e pela indústria cultural em geral.” (HERSCHMANN, 2005, p. 73).

Na contemporaneidade, através da participação em programas de TV ou ainda em outros eventos promocionais, alguns indivíduos de condição de vida simples, sem muitos recursos materiais, transformam-se em fenômenos da mídia rapidamente. E, em poucos meses, muitos acabam por usufruir de um sucesso repentino, conquistando uma melhor condição financeira que lhes possibilita a aquisição de bens de valor elevado. Alguns dos Mcs do chamado funk ostentação, corrente na qual poderíamos aproximar os exemplos nessa seção elencados, são exemplos de um sucesso repentino. ${ }^{18}$ O funk ostentação foi tema de um documentário, ao final do ano de 2012, e de reportagem de uma conhecida revista brasileira. Embora, na visão de seus intérpretes, tais músicas retratem possibilidades de vida a serem alcançadas pela população de periferia, é válido problematizar de que modos tais possibilidades poderiam ser efetivadas.

Em determinados versos da música Onde eu chego eu paro tudo, é possível pensar que o uso de artefatos de marcas de grife e de automóveis caros seja propiciado pela prática de atividades ilícitas, tais como roubos e furtos. Nos referimos aqui, especificamente, aos versos "correria traz fartura, fortuna traz alegria" e "nós investe no poder e usufrui da putaria". No ambiente da periferia é de conhecimento geral que "aqueles que fazem correria" são os sujeitos envolvidos em práticas ilícitas, a exemplo do tráfico de drogas e do comércio de máquinas caça-níqueis. ${ }^{19}$

De modo semelhante ao exposto pela música Onde eu chego eu paro tudo, a música Rolê da Haybusa, de $M c$ Dedé, também visibiliza a relação entre popularidade e consumo de caros artefatos de vestuário (a exemplo de roupas Hollister e Abercrombie \& Fitch ${ }^{20}$, tal como podemos observar no recorte da mesma:

18 Produzido por Renato Barreiros e Konrad Dantas e disponibilizado no site Youtube: http://www.youtube.com/ watch?v=5V3ZK6jAuNI. Acesso em 01 de abr. 2013. Ver: http://vejasp.abril.com.br/materia/funk-ostentacao-paulista. Acesso em 05 abr. 2013.

19 Como docentes já ouvimos, alguns alunos, que a expressão fazer correrias por fora está relacionada a tais práticas. 20 Exemplos de algumas peças da empresa Hollister podem ser verificados em http://www.shopmania.com. br/q-hollister-brasil. Já as peças da Abercrombie Fitch podem ser visibilizadas em http://www.outlethouse.com.br/ ecommerce_site/categoria_9186-9468_6987_Roupas-Masculinas-Abercrombie-Fitch. Acesso em 15 jan. 2012. 
Área vip, whisky, no camarote só as top de elite

No baile (HAHA), nóis porta o kit

Tem Hollister e Abercrombie fitch

Meninas solteiras o baile é de vocês

Vem dançando uma de cada vez (Rolê da Haybusa - $\boldsymbol{M c}$ Dedé) ${ }^{21}$

Ao problematizar com as alunas a relação dos artefatos de consumo descritos em ambas as músicas e a real possibilidade financeira de serem adquiridos, as mesmas destacaram a realização de atividades ilícitas como meio para a conquista de tais bens, como é possível visualizar em suas falas:

Pesquisadora: Haybusa é uma moto caríssima! Vocês acham que os caras que cantam essas músicas têm dinheiro para comprar?

Isabelly: Têm! Porque eles invadem o lugar e "pegam" né?

Amanda: Mas tu achas que os que têm Haybusa conseguem comprar Haybusa como? Vendendo droga!

Isabelly: É patrão! Eles são patrão!

É possível pensar que as músicas alinhadas com o funk ostentação visibilizem a ideia de Zigmund Bauman (2005) de que, na contemporaneidade, o mundo configura-se como um palco de performances no (e do) qual somos consumidores de bens de consumo, de bens culturais e até mesmo de relacionamentos.

\section{Encerrando para pensar...}

[...]eu acho que discursos, na verdade, habitam corpos. Eles se acomodam em corpos; os corpos na verdade carregam discursos como parte de seu próprio sangue. (BUTLER, 2002, p. 163)

As palavras de Butler (2002) são profícuas para pensar como os diferentes discursos, a exemplo daqueles elencados neste estudo, acabam por constituir distintos modos de ser uma jovem aluna na contemporaneidade. O próprio conceito de juventude remete a ideia de categoria plural, fato que a afasta de um modo único para descrevê-la e contextualizá-la (GARBIN, 2009 e DAYRELL 2007). Contudo, na atualidade, certas características, tais como beleza, espontaneidade, vitalidade e versatilidade acabam por ser naturalmente associadas à condição juvenil, exaltadas por diversos discursos circulantes em nossa sociedade, a exemplo do discurso midiático e do discurso médico.

A respeito da produtividade das diversificadas mídias na constituição dos sujeitos, Rosa Fischer afirma que "[...] a mídia não apenas veicula, mas também constrói discursos e produz significados, identidades e sujeitos [...]" (FISCHER, 2001, p. 588). Vale pontuar que, segundo a referida autora, a(s) feminilidade(s) acabam por ser "reforçadas, imaginadas, dinamizadas, polemizadas, enfim, construídas na cultura." (FISCHER, 2001, p. 591). A dimensão cultural também é destaca por Juarez Dayrell (2007) como espaço de constituição das identidades juvenis, através das práticas, dos símbolos e dos rituais compartilhados entre os pares.

21 Mc Dedé é o nome artístico de Josley Caio Faria, cantor de funk. 
Dessa forma, entendemos como necessário continuar o estudo e a problematização acerca das formas com que os discursos visibilizados pelas músicas escutadas por alunas produzem modos de viver a feminilidade na atualidade, pois as mesmas armazenam em seus celulares tanto músicas lascivas como românticas apreciadas, muitas vezes, tão somente pela sua "batida" e pelo seu "ritmo". Entendemos ainda que visibilizar e problematizar os modos de ser e de viver das alunas jovens, nos tempos atuais, é possibilitar uma melhor compreensão das condições que organizam a constituição das culturas juvenis femininas. Pensamos que muitos outros discursos poderiam ser aqui problematizados; não em procura de soluções mágicas e imediatas, mas sim buscando dar visibilidade para dimensões ainda pouco estudadas no que se refere a juventude feminina. Encerramos com as palavras de Guacira Louro: "talvez seja mais produtivo para nós, educadoras e educadores, deixar de considerar toda essa diversidade de sujeitos e práticas como um 'problema' e passar a pensá-la como constituinte do nosso tempo" (LOURO, 2003, p. 51).

\section{Referências}

BAUMAN, Zygmunt. Vidas desperdiçadas. Rio de Janeiro: Jorge Zahar, 2005. BAUMAN, Zygmunt. Modernidade líquida. Rio de Janeiro: Jorge Zahar, 2001.

BRASIL. Lei $N^{\circ}$ 9.394, de 20 de dezembro de 1996. Estabelece as diretrizes e bases da educação nacional.

BRASIL. Secretaria de Educação Fundamental. Parâmetros Curriculares Nacionais: pluralidade cultural, orientação sexual. Secretaria de Educação Fundamental. Brasília. MEC/SEF, 1997 (volume 10).

BRASIL. Ministério da Educação. Resolução CNE/CNB n4, de 13 de julho de 2010. Diretrizes Curriculares para Educação Básica, 2010. Disponível em: $<$ http://portal.mec.gov.br/index. php?option=com_docman\&task=doc_download\&gid=6704\&Itemid=> Acesso em 18 mai. 2012.

BUTLER, Judith. Problemas de gênero: feminismo e subversão da identidade. 2. ed. Tradução de: Renato Aguiar. Rio de Janeiro: Civilização Brasileira, 2008.

BUTLER, Judith. Como os corpos se tornam matéria. In: PRINS, Baukje; MEIJER, Irene. In: Revista Estudos Feministas, v.10, n.1, jan. 2002, p. 155-167.

COSTA, Marisa Vorraber; SILVEIRA, Rosa Hessel; SOMMER, Luis Henrique. Estudos culturais, educação e pedagogia. Revista Brasileira de Educação, n. 23, maio/ago. 2003, p. 36-61.

DAYRELL, Juarez. O jovem como sujeito social. Revista Brasileira de Educação. Rio de Janeiro. n. 24, set/out/nov/dez. 2003, p. 40-52.

ESCOSTEGUY, Ana Carolina. Os Estudos Culturais. 2001. Disponível em:

$<$ http://www.pucrs.br/famecos/pos/cartografias/artigos/estudos culturais ana.pdf $>$. Acesso em: 14 maio 2012.

FISCHER, Rosa Maria Bueno. Mídia e educação da mulher: sobre modos de enunciar o feminino na TV. Revista Estudos Feministas, Florianópolis, v. 9, n. 2, 2001/2, p. 586-599.

FOUCAULT, M. História da sexualidade II- O uso dos prazeres. 13 ed. São Paulo: Graal, 2009.

FOUCAULT, M. História da sexualidade I- A vontade de saber. 18. ed. São Paulo: Graal, 2007.

GARBIN, Elisabete M. Conectados por um fio: alguns apontamentos sobre internet, culturas juvenis contemporâneas e escola. In: Salto para o futuro - Juventude e escolarização: os sentidos 
do Ensino Médio. Ano XIX, boletim 18, p. 30-40, novembro de 2009.

HALL, Stuart. A centralidade da cultura: notas sobre as revoluções de nosso tempo. In: Educação \& Realidade. Porto Alegre. v. 22, n. 2, p. 15 - 46, jul./dez. 1997.

HERSCHMANN, Micael. O funk e o hip-hop invadem a cena. Rio de Janeiro: Editora

UFRJ, 2000.

LARROSA, Jorge. Notas sobre a experiência e o saber de experiência. Revista Brasileira de Educação, n. 19, Jan./Fev./Mar./Abr. 2002.

LARROSA, Jorge. Tecnologias do eu e educação. In: SILVA, Tomaz Tadeu. O sujeito da educação. Petrópolis: Vozes, 1994, p.35-86.

LAURETIS, Teresa de. A tecnologia do gênero. Tradução de Suzana Funck. In: HOLLANDA, Heloisa Buarque de (Org.), Tendências e impasses - O feminismo como crítica da cultura. Rio de Janeiro: Rocco, 1994. p. 206-242.

LOURO, Guacira Lopes. Currículo, gênero e sexualidade: o "normal", o "diferente" e o "excêntrico". In: LOURO, Guacira; NECKEL, Jane Felipe; GOELLNER, Silvana Vilodre (Orgs.). Corpo, gênero e sexualidade: um debate contemporâneo na educação. Petrópolis: Vozes, 2003, p. 41-52.

MOREIRA, Antônio Flávio Barbosa e SILVA JUNIOR, Paulo Melgaço. Periferias, sexualidades e educação para a sexualidade: desafios para as práticas curriculares. In: SOBREIRA, Henrique Garcia (Org.). Educação, culturas e comunicação nas periferias urbanas. Rio de Janeiro: Lamparina, 2010. p. 21-40.

NELSON, Cary et al. Estudos Culturais: uma introdução. In: SILVA, Tomaz Tadeu (Org.). Alienígenas na sala de aula: uma introdução aos estudos culturais em educação. Petrópolis: Vozes, 1995. p. 7-38.

PETERS, Michael. Pós-estruturalismo e filosofia da diferença. Uma introdução. Belo Horizonte: Autêntica, 2000.

RIBEIRO, Claudia Maria. Os jogos na educação para a sexualidade. In: In: RIBEIRO, Claudia Maria e SOUZA, Ila Maria Silva (Orgs.). Educação Inclusiva: tecendo gênero e diversidade sexual nas redes de proteção. Larvas: Ed UFLA, 2008. p.96-110.

SANTOS, Luiz Henrique Sacchi dos. Heteronormatividade \& Educação. In: Tá difícil de falar sobre sexualidade na escola? SOMOS: Porto Alegre. p. 26-36. 2009. Disponível em: http://issuu. com/somoslgbt/docs/tadificilfalarsobresexualidade. Acesso em 26 set. 2014.

SARMENTO, Manuel Jacinto. O estudo de caso etnográfico em educação. In: ZAGO, Nadir, CARVALHO, Marília P. VILELA, Rita A.T. Itinerários de pesquisa: perspectivas qualitativas em sociologia da educação. Rio de Janeiro: DP\&A, 2011. p.137-179.

SEFFNER, Fernando. Sigam-me os bons: apuros e aflições nos enfrentamentos ao regime da heteronormatividade no espaço escolar. In: Educação e Pesquisa. São Paulo, v. 39, n. 1, p. 145159, jan./mar. 2013.

SCOTT, Joan. Gênero: uma categoria útil de análise histórica. In: Educação \& Realidade. Porto Alegre, vol. 20, n. 2, jul./dez, p. 71-99. 1995.

WEEKS, Jeffrey. O corpo e a sexualidade. In: LOURO, Guacira Lopes (Org.). O corpo educado: pedagogias da sexualidade. Tradução Tomaz Tadeu da Silva. $3^{\text {a }}$ ed. Autêntica: Belo Horizonte, 2010.p. 35-82.

VEIGA-NETO, Alfredo. É preciso ir aos porões. In: Revista Brasileira de Educação, v. 17, n. 50, p. 267-282, maio-ago, 2012.

VEIGA-NETO Alfredo. Cultura, culturas e educação. In: Revista Brasileira de Educação, Campinas, n. 23, p. 5-15, maio/jun/jul/.ago. 2003.

WOODS, Peter. La escuela por dentro: La etnografía en la investigación educativa. Barcelona: Paidós/MEC, 1987. 